\title{
Salivary duct carcinoma: a case report with cytological and pathological features
}

Kuniaki Hirai', Naomi Kawaguchi', Kyoko Nambu', Asuka Sekiya', Toshimasa Sakakima², Masashi Matsuyama', Fumimasa Etori', Yoichi Yokota $^{3}$, Hiromichi Shirato ${ }^{3}$, Naoki Watanabe' ${ }^{1}$, Takafumi Naiki ${ }^{2}$, Tetsuya Yamada ${ }^{4}$ and Takuji Tanaka ${ }^{1,5^{*}}$

${ }^{*}$ Correspondence: takutt@gmhosp.gifu.gifu.jp

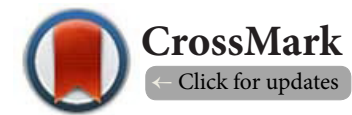

'Department of Diagnostic Pathology and Research Center of Diagnostic Pathology, Gifu Municipal Hospial, 7-1 Kashima-cho, Gifu City, Japan.

2Department of Central Laboratory, Gifu Municipal Hospial, 7-1 Kashima-cho, Gifu City, Japan.

${ }^{3}$ Department of Otolaryngology, Gifu Municipal Hospial, 7-1 Kashima-cho, Gifu City, Japan.

${ }^{4}$ Department of Diagnostic Pathology, Kizawa Memory Hospital, 590 Shimofurui, Frui-machi, Minokamo City, Japan.

${ }^{5}$ Department of Tumor Pathology, Gifu University Graduate School of Medicine, 1-1 Yanagido, Gifu City, Japan.

\begin{abstract}
A 55-year-old Japanese man presented with rapidly growing tumor in the left parotid region without any symptoms. Based on the fine-needle aspiration cytology report of parotid epithelial malignant tumor (suggestive of salivary duct carcinoma), the left parotidectomy was performed. Histopathology and immunohistochemistry examinations revealed features of salivary duct carcinoma. Although salivary duct carcinoma comprising a small proportion of salivary gland tumors and is known to be aggressive, he is free from recurrence and metastases 36 months after the surgery and radiation therapy.
\end{abstract}

Keywords: Salivary duct carcinoma, parotid gland, fine-needle aspiration cytology, histopathology, immunohistochemistry

\section{Introduction}

Salivary duct carcinoma is a rare malignant epithelial tumor, which accounts less than $1 \%$ of epithelial salivary gland neoplasms [1]. Seventy-five percent of salivary duct carcinomas occur in the parotid gland [1]. The peak incidence is in the seventh decade of life, and its occurrence in patients under age50 year is uncommon [1]. Because of similar histologic features, salivary duct carcinoma is often compared to ductal carcinoma [2], atypical ductal hyperplasia $[3,4]$ of the breast, but the majority of patients are men. This malignancy is one of the most aggressive salivary gland malignancies [1]. Local invasion, frequent lymphatic and hematogenous metastasis, and poor prognosis characterize the biologic behavior of this malignancy.

Because of its low incidence [1], the cytological and pathological features have not been elucidated sufficiently. This case report illustrates both the cytological and pathological features of salivary duct carcinoma that developed in a Japanese adult male.

\section{Case presentation}

On June 9, 2011, a 55-year-old man presented our hospital with a progressively growing tumor mass on the left side of whis neck. He had no history of diseases. Physical examination revealed a single painless, firm, and mobile $3 \mathrm{~cm}$ mass in the parotid area. Facial nerve function was intact. At presentation, the results of routine serum biochemistry tests were normal, with the exception of the level of total bilirubin $(1.5 \mathrm{mg} / \mathrm{dl})$, blood sugar (118 mg/dl). Computed tomography (CT) scan showed a tumor mass $(2.4 \mathrm{~cm}$ in diameter) almost entirely replacing the left parotid gland (Figure 1 ).

Fine-needle aspiration cytology from the parotid tumor showed many epithelial tumor cells. They are arranged in cohesive clusters, which have a cribriform architectural pattern (Figure 2a). Individual tumor cells are scattered at the periphery of the cellular clusters. Tumor cells are round to polygonal with abun-dant and finely granular cytoplasm. They have medium to large, moderately pleomorphic and hyperchromatic nuclei with granular chromatin (Figures $\mathbf{2} \mathbf{b}$ and $\mathbf{2 c}$ ). Based on the cytological findings, we diagnosed this tumor as parotid epithelial malignant tumor (suggestive of salivary duct carcinoma).

The left parotidectomy was performed in July 20, 2011. As shown in Figure $3 a$, a nodular tumor $(2.8 \mathrm{~cm}$ in diameter replaced the parotid gland. Cut-surface of the resected tumor was yellowish white, unencapsulated, and poorly circumscribed 
Hirai et al. Pathology Discovery 2014,

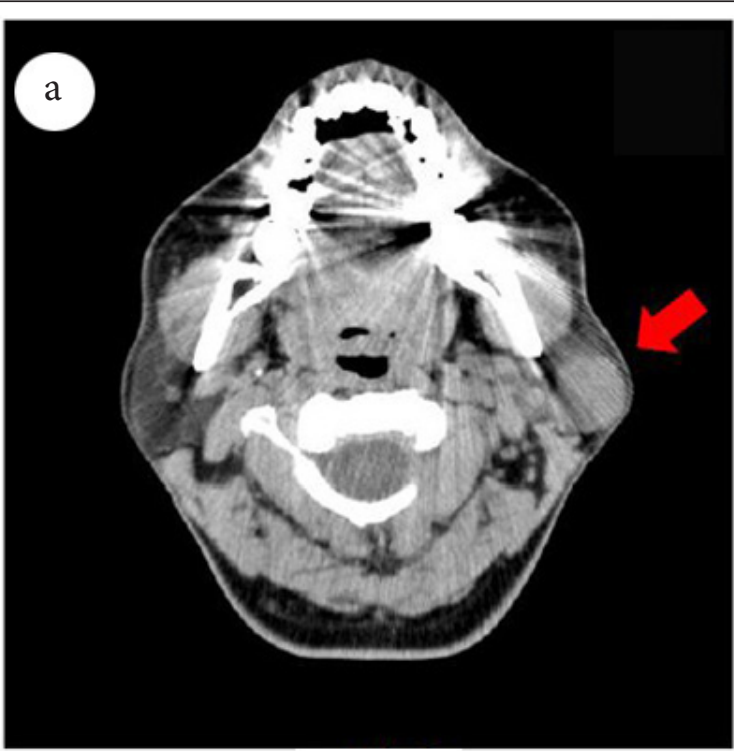

axial

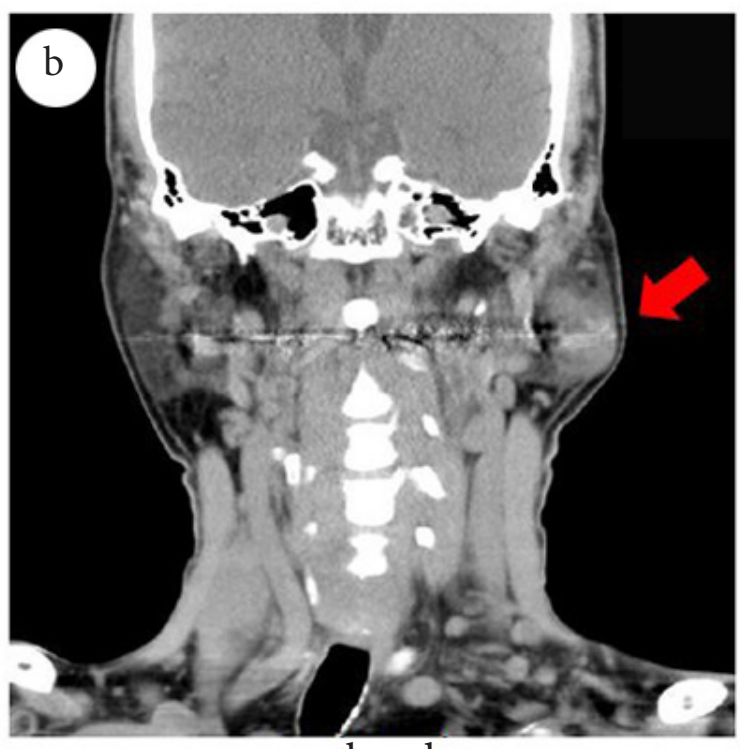

colonal

Figure 1. CT examination reveals the left parotid tumor. (a) axial and (b) confocal views.

(Figure 3b). The tumor was multi-nodular and contained necrosis and small cystic lesions. Pathological examination showed that round and well-circumscribed tumor nodules are composed of moderately pleomorphic ductal epithelial cells (Figure 4a). These cells surround a core of comedonecrosis (Figure 4b). Solid nests of tumor have scattered necrotic cells with surrounding retraction artifact. These findings suggested salivary duct carcinoma. To confirm the pathological diagnosis, immunohistochemistry using antibodies against gross cytic disease fluid protein-15 (GCDFP15), androgen receptor (AR), human epithelial growth factor receptor 2 (HER2/neu), S-100, and epithelial membrane antigen (EMA) was conducted and showed

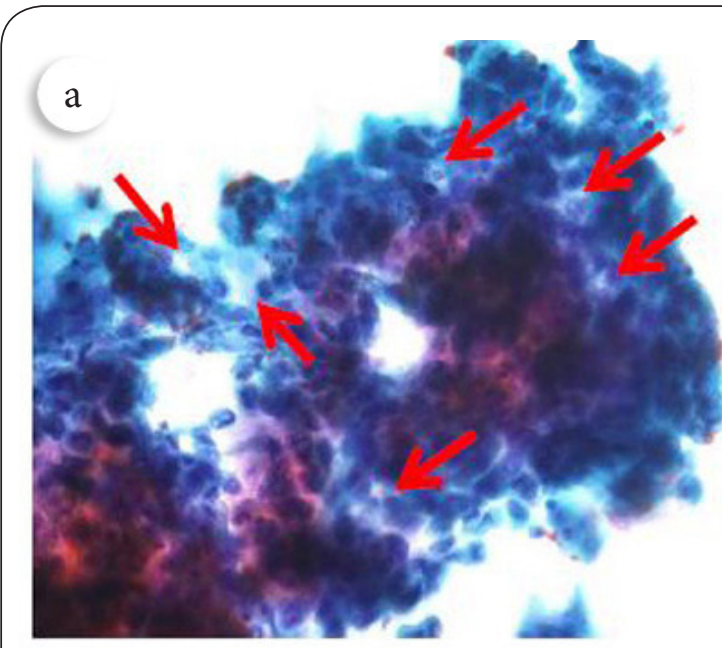

-
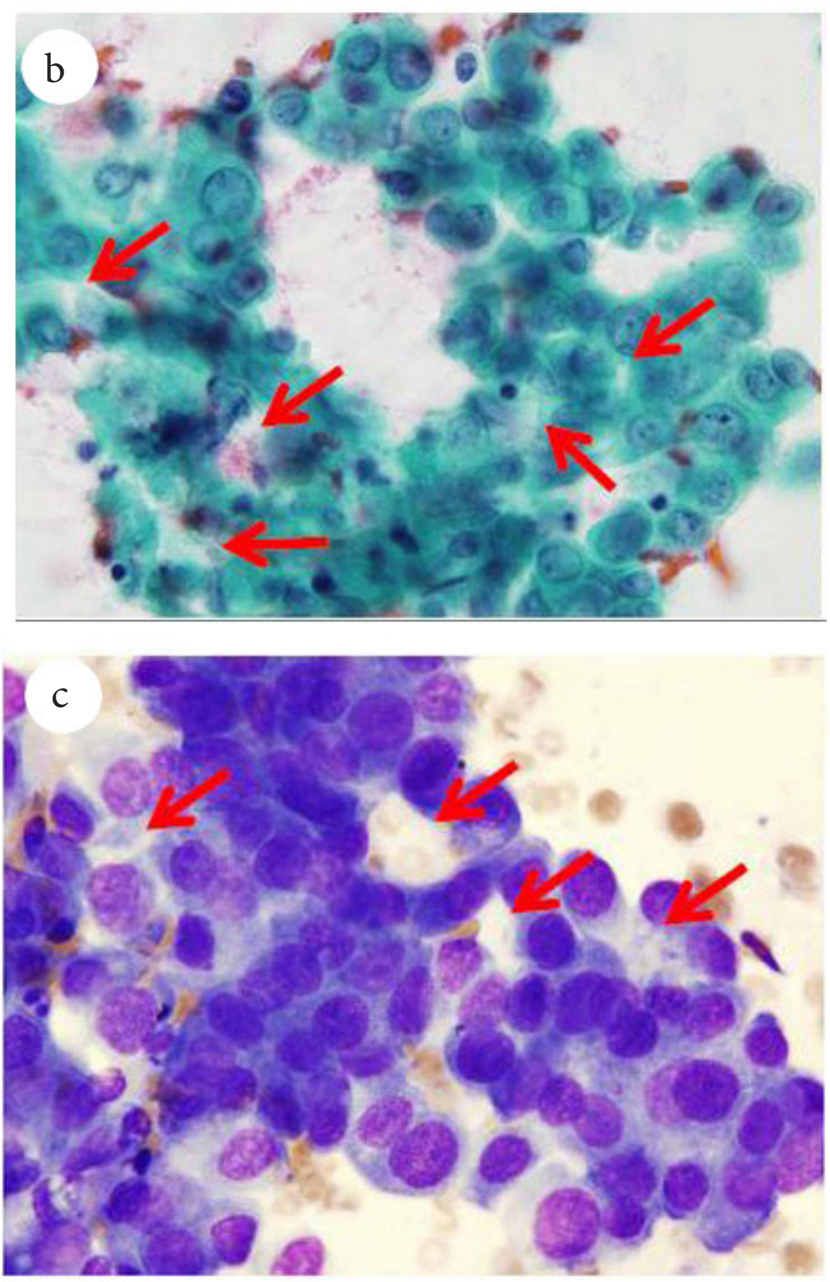

Figure 2. Representative features of fine needle aspiration cytology. (a) A sheet of cancer cells with cribriform and/or microcystic patterns; (b) Cancer cells with prominent nucleoli are round to polygonal with abundant and finely granular cytoplasm; and (c) They have hyperchromatic nuclei with granular chromatin. Arrows indicate cribriform or microcystic structures. (a) and (b), Papanicolaou stain and (c) Giemsa stain. Original magnifications, (a) x160, (b) and (c) x400. 


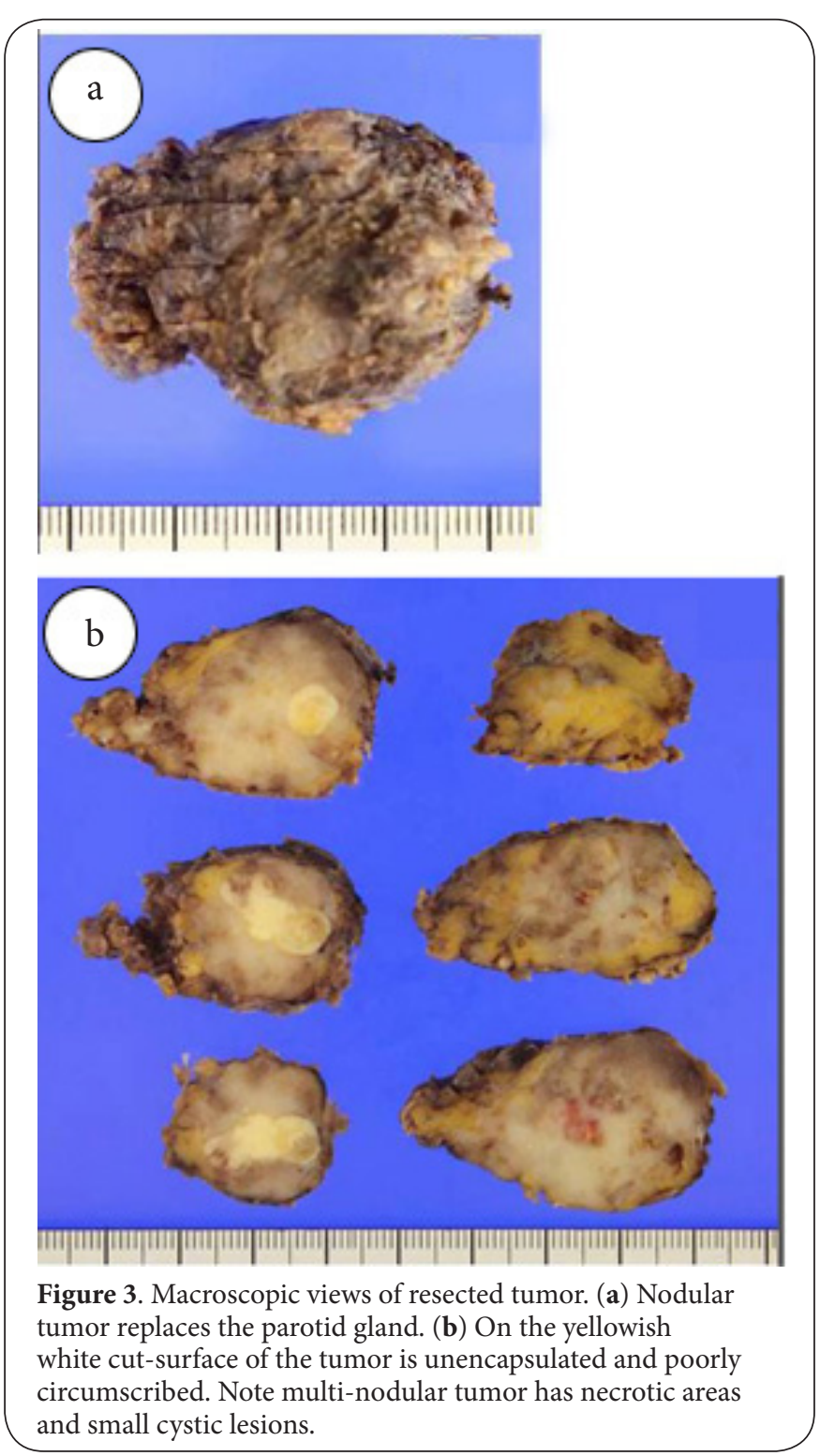

that malignant cells were immunoreactive for AR (Figure 5a), HER2/neu (Figure 5b), and EMA (Figure 5c). However, cancer cells were negative for S-100 (Figure 5d). A few cancer cells were positive for GCDFP15 (Figure 5e). Positive rate of cancer cells against Ki-67 antigen (MIB1) was about 50\% (Figure 5f). Other immunohistochemistry showed positive for AE1/AE3 and cytokeratin 7, and negative for a-smooth muscle actin, p53, and p63 [5].

Postoperatvely the patient received a total of $50 \mathrm{~Gy}$ (2 Gy x 25) of radiation. He is currently under close follow-up every four months and he is well 36 months after the surgery.

\section{Discussion and conclusions}

A rare case of salivary duct carcinoma in Japanese man was presented. Cancer cells in this case exhibited pathological and immunohistochemical findings similar to those reported

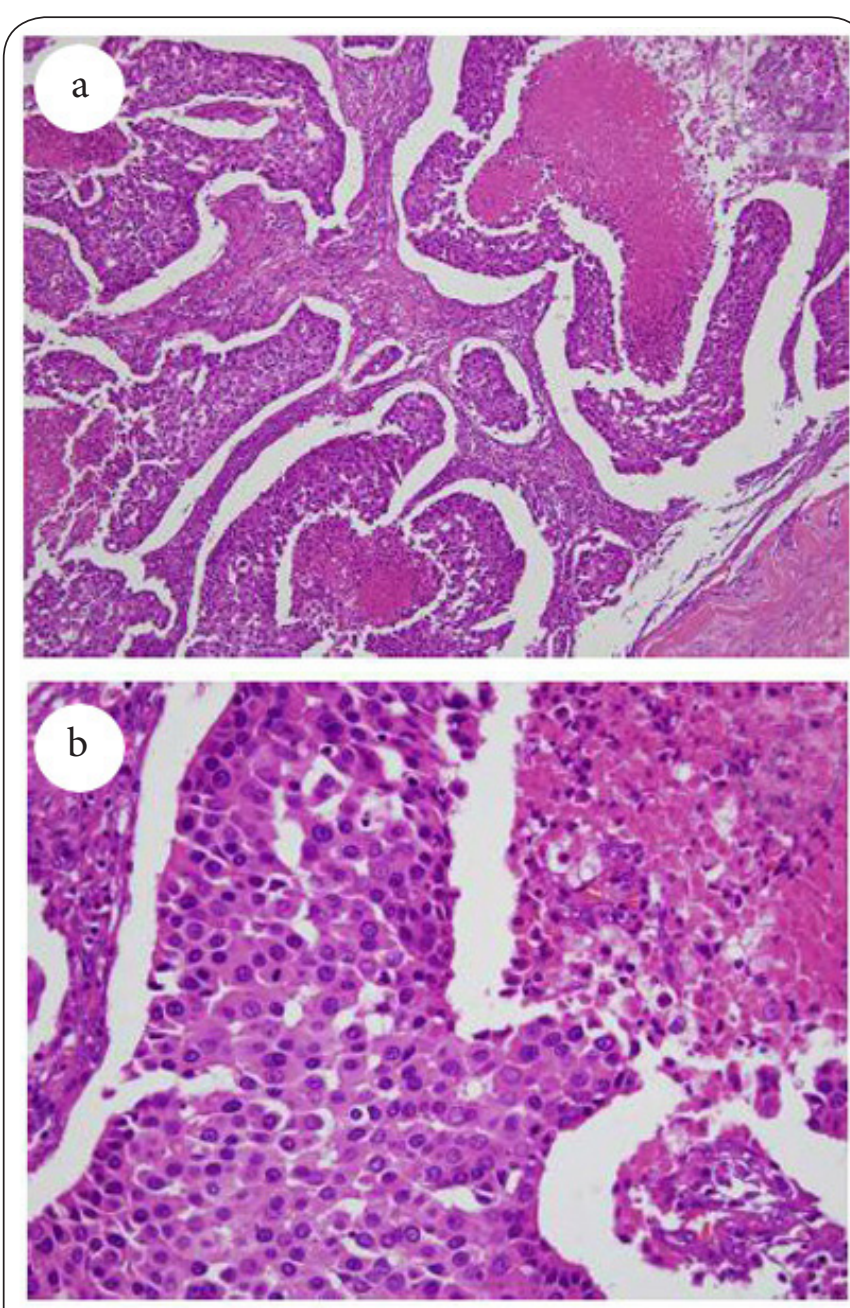

Figure 4. Representative histopathology of the tumor. (a) A tumor nodules is composed of cancer cells with microcystic lesions and comedonecrosis. ductal epithelial cells. (b)

Cancer cells have moderately pleomorphic nuclei. (a) and (b), Heamatoxilin eosin stain. Original magnification, (a) x40 and (b) $\mathrm{x} 160$.

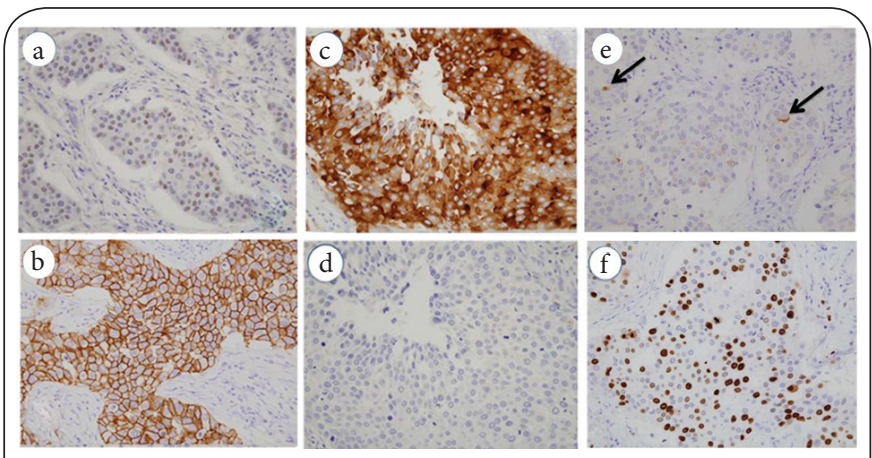

Figure 5. Representative immunohistochemistry of the tumor. The cancer cells are positive for (a) AR, (b) HER2/ neu, and (c) EMA, but negative for (d) S-100. Only a few cancer cells (arrows) are immunoreactive for (e) GCDFP15. Positive rate of (f) MIB1-reactive nuclei is about $50 \%$. Original magnification, (a)-(f), x160. 
Hirai et al. Pathology Discovery 2014,

previously [1,6-12]. Although salivary duct carcinoma is one of the most aggressive salivary gland malignancies, the patient reported here is free of metastasis and recurrence 36 months after the surgery. In addition, this type of cancer strongly expr-essed HER2/neu is more aggressive than those without HER2/neu expression $[1,13]$. The reasons of favorable prognosis of this patient are not known. However, some correlation of prognosis to tumor size was reported: less than $3 \mathrm{~cm}$ indicated a better prognosis. Therefore, the relatively small size $(2.8 \mathrm{~cm})$ of the tumor size in conjunction with low MIB-1-positive index and p53 negative cancer cells [14] may influence the prognosis. Our case suggested a low-grade salivary duct carcinoma [3], but immunohistochemical findings of S-100 and HER2/neu were different from those reported by Brandwein-Gensler et al., [3].

An uncommon and high-grade malignant neoplasm, salivary duct carcinoma, is derived from intralobular and interlobular excretory ducts. Its histopathologic characteristics have a striking resemblance to ductal carcinoma of the breast. In 1968, Kleinsasser et al., [15] first used the term salivary duct carcinoma. Since other salivary gland carcinomas are derived from the duct system and exhibit ductal differentiation, the term salivary duct carcinoma is probably not the best choice to identify a specific category of salivary gland carcinoma. Although Brandwein et al., [16] proposed the term cribriform salivary carcinoma of excretory duct, at present salivary duct carcinoma has become the established terminology.

As to the cytological features of salivary duct carcinoma, viable tumor cells in cytologic specimens are often in a background of necrosis. As found in this case, cancer cells are arranged in cohesive clusters, which sometimes have a cribriform or papillary architectural pattern [1]. Other cytologic features in this case were similar to those reported previously [1]. Therefore, cytological diagnosis of salivary duct carcinoma is possible [7].

The most characteristic histopathological feature is variably sized, rounded, solid or cystic nodules of tumor cells. These findings are similar to those of intraductal carcinoma of the breast $[1,2]$. Comedonecrosis is characteristic of salivary duct carcinoma and is one of the biomarkers of this malignancy. In this case, we noticed comedonecrosis in the cytologic and histologic specimens. Immunohistochemcal observation in this case revealed similar findings reported previously. Cancer cells were strongly positive for AR [17] and HER2/neu [13], but negative for S-100 [1]. However, only a few cancer cells were weakly positive for apocrine marker GCDFP-15, in contrast to previous reports $[18,19]$.

\section{Competing interests}

The authors declare that they have no competing interests.

\section{Authors' contributions}

\begin{tabular}{|c|c|c|c|c|c|c|c|c|c|c|c|c|c|}
\hline $\begin{array}{l}\text { Authors' } \\
\text { contributions }\end{array}$ & KH & NK & KN & AS & TS & MM & FE & YY & HS & NW & TN & TY & TT \\
\hline $\begin{array}{l}\text { Research concept } \\
\text { and design }\end{array}$ & $\checkmark$ & $\checkmark$ & -- & -- & -- & $\checkmark$ & $\checkmark$ & -- & -- & $\checkmark$ & $\checkmark$ & $\checkmark$ & $\checkmark$ \\
\hline $\begin{array}{l}\text { Collection and/or } \\
\text { assembly of data }\end{array}$ & $\checkmark$ & $\checkmark$ & $\checkmark$ & $\checkmark$ & $\checkmark$ & $\checkmark$ & $\checkmark$ & $\checkmark$ & $\checkmark$ & $\checkmark$ & $\checkmark$ & $\checkmark$ & -- \\
\hline $\begin{array}{l}\text { Data analysis and } \\
\text { interpretation }\end{array}$ & $\checkmark$ & $\checkmark$ & $\checkmark$ & $\checkmark$ & $\checkmark$ & $\checkmark$ & $\checkmark$ & $\checkmark$ & $\checkmark$ & $\checkmark$ & $\checkmark$ & $\checkmark$ & $\checkmark$ \\
\hline Writing the article & $\checkmark$ & -- & -- & -- & -- & -- & -- & -- & -- & -- & -- & -- & $\checkmark$ \\
\hline $\begin{array}{l}\text { Critical revision of } \\
\text { the article }\end{array}$ & -- & -- & -- & -- & -- & $\checkmark$ & $\checkmark$ & -- & -- & $\checkmark$ & $\checkmark$ & -- & $\checkmark$ \\
\hline $\begin{array}{l}\text { Final approval of } \\
\text { article }\end{array}$ & $\checkmark$ & $\checkmark$ & $\checkmark$ & $\checkmark$ & $\checkmark$ & $\checkmark$ & $\checkmark$ & $\checkmark$ & $\checkmark$ & $\checkmark$ & $\checkmark$ & $\checkmark$ & $\checkmark$ \\
\hline
\end{tabular}

\section{Acknowledgement}

This work was partly supported by a Grant-in-Aid for the $3^{\text {rd }}$ Terms Comprehensive 10-Year Strategy for Cancer Control from the Ministry of Health, Labour and Welfare of Japan.

\section{Publication history}

Editor: Hiroko Kuwabara, Osaka Medical College, Japan.

EIC: Markus H. Frank, Harvard Medical School, USA.

Received: 30-Jul-2014 Final Revised: 12-Sep-2014

Accepted: 17-Sep-2014 Published: 25-Sep-2014

\section{References}

1. Ellis GL and Auclair PL. Tumors of the Salivary Glands. AFIP Atlas of Tumor Pathology: Armed Forces Institute of Pathology and American Registry of Pathology, Washington, D.C., 2008; 322-332.

2. Fyrat $P$, Cramer H, Feczko JD, Kratzer S, Layfield LJ, Eisenhut CC and Glant $\mathrm{MD}$. Fine-needle aspiration biopsy of salivary duct carcinoma: report of five cases. Diagn Cytopathol. 1997; 16:526-30. | PubMed

3. Brandwein-Gensler M, Hille J, Wang BY, Urken M, Gordon R, Wang LJ, Simpson JR, Simpson RH and Gnepp DR. Low-grade salivary duct carcinoma: description of 16 cases. Am J Surg Pathol. 2004; 28:1040-4. | Article | PubMed

4. Fahim L, Weinreb I, Alexander C and Perez Ordonez B. Epithelial proliferation in small ducts of salivary cystadenoma resembling atypical ductal hyperplasia of breast. Head Neck Pathol. 2008; 2:213-7. | Article | PubMed Abstract I PubMed Full Text

5. Kawaguchi N, Nambu K, Sekiya A, Furuta C, Miyamae R, Niwa R, Sakakima T, Matsuyama M, Etori F, Yamada T, Yokota $Y$ and Shirato H. A case of salivary duct carcinoma in the parotid gland (in Japanese). Annu. Gifu Municipal Hosp. 2013; 33:23-25.

6. Colecchia M, Frigo B and Leopardi OM. Salivary duct carcinoma of the parotid gland. Report of a case with cytologic and immunocytochemical findings on fine needle aspiration biopsy. Acta Cytol. 1997; 41:593-7. | PubMed

7. Elsheikh TM, Bernacki EG, Jr. and Pisharodi L. Fine-needle aspiration cytology of salivary duct carcinoma. Diagn Cytopathol. 1994; 11:47-51. | Article | PubMed

8. Gilcrease MZ, Guzman-Paz M, Froberg K and Pambuccian S. Salivary duct carcinoma. Is a specific diagnosis possible by fine needle aspiration cytology? Acta Cytol. 1998; 42:1389-96. | PubMed

9. Kinnera VS, Mandyam KR, Chowhan AK, Nandyala R, Bobbidi VP and Vutukuru VR. Salivary duct carcinoma of parotid gland. J Oral Maxillofac Pathol. 2009; 13:85-8. | Article | PubMed Abstract | PubMed Full Text

10. Moriki T, Ueta S, Takahashi T, Mitani M and Ichien M. Salivary duct carcinoma: cytologic characteristics and application of androgen receptor immunostaining for diagnosis. Cancer. 2001; 93:344-50. | Article I PubMed

11. Valeri RM, Hadjileontis C, Skordalaki A, Pandidou A, Vahtsevanos C and Destouni H. Salivary duct carcinoma of the parotid gland: report of a rare case with a comparative study of aspiration cytology and 
Hirai al. Pathology Discovery 2014,

histomorphology. Acta Cytol. 2005; 49:61-4. | PubMed

12. Yamada S, Nabeshima A, Tabata T, Guo X, Tasaki T, Wang KY, Shimajiri $S$ and Sasaguri $Y$. Invasive salivary duct carcinoma ex pleomorphic adenoma of the parotid gland: a teaching case giving rise to the genuine diagnostic difficulty on an inadequate cytology specimen. Diagn Pathol. 2012; 7:61. | Article | PubMed Abstract | PubMed Full Text

13. Nabili V, Tan JW, Bhuta S, Sercarz JA and Head CS. Salivary duct carcinoma: a clinical and histologic review with implications for trastuzumab therapy. Head Neck. 2007; 29:907-12. | Article | PubMed

14. Kim HJ, Yoo YS, Park K, Kwon JE, Kim JY and Monzon FA. Genomic aberrations in salivary duct carcinoma arising in Warthin tumor of parotid gland: DNA microarray and HER2 fluorescence in situ hybridization. Arch Pathol Lab Med. 2011; 135:1088-91. | Article | PubMed

15. Kleinsasser $\mathrm{O}$, Klein $\mathrm{HJ}$ and Hubner G. [Salivary duct carcinoma. A group of salivary gland tumors analogous to mammary duct carcinoma]. Arch Klin Exp Ohren Nasen Kehlkopfheilkd. 1968; 192:100-5. I PubMed

16. Brandwein MS, Jagirdar J, Patil J, Biller $\mathrm{H}$ and Kaneko M. Salivary duct carcinoma (cribriform salivary carcinoma of excretory ducts). A clinicopathologic and immunohistochemical study of 12 cases. Cancer. 1990; 65:2307-14. | PubMed

17. Jaspers HC, Verbist BM, Schoffelen R, Mattijssen V, Slootweg PJ, van der Graaf WT and van Herpen CM. Androgen receptor-positive salivary duct carcinoma: a disease entity with promising new treatment options. J Clin Oncol. 2011; 29:e473-6. | Article | PubMed

18. Wick MR, Ockner DM, Mills SE, Ritter JH and Swanson PE. Homologous carcinomas of the breasts, skin, and salivary glands. A histologic and immunohistochemical comparison of ductal mammary carcinoma, ductal sweat gland carcinoma, and salivary duct carcinoma. Am J Clin Pathol. 1998; 109:75-84. | PubMed

19. Yamamoto $H$, Uryu $H$, Segawa $Y$ and Tsuneyoshi M. Aggressive invasive micropapillary salivary duct carcinoma of the parotid gland. Pathol Int. 2008; 58:322-6. | Article | PubMed

\section{Citation:}

Hirai K, Kawaguchi N, Nambu K, Sekiya A, Sakakima T, Matsuyama M, Etori F, Yokota Y, Shirato $H$, Watanabe N, Naiki T, Yamada T and Tanaka T. Salivary duct carcinoma: a case report with cytological and pathological features. Pathol Discov. 2014; 2:6.

http://dx.doi.org/10.7243/2052-7896-2-6 